\title{
Body Weight Disorders and Co-morbidities in Patients with Chronic Obstructive Pulmonary Disease
}

\author{
Esmaeil Alibakhshi ${ }^{1,2 *}$ \\ ${ }^{1}$ Parc Sanitari Sant Joan de Deu (PSSJD), Faculty of Medicine, Barcelona University, Spain \\ ${ }^{2}$ Exercise Physiology Research Center, Life style Institute, Baqiyatallah University of Medical Science, Iran
}

Submission: December 27, 2017; Published: January 11, 2018

*Corresponding author: Esmaeil Alibakhshi, Parc Sanitari Sant Joan de Deu (PSSJD), Faculty of Medicine, Barcelona University, Spain, Tel: 34603482230, +34 931161430; Email: ealibaal7@alumnes.ub.edu

\begin{abstract}
Abstact
Chronic obstructive pulmonary disease (COPD) is a pulmonary epidemic which is the third leading cause of death in the world in 2030. Although weight loss is very common in patients with COPD, but previous studies have shown that about $65 \%$ of patients with COPD have overweight or obesity, which can be due to physical inability and drug therapy. Due to cardiovascular disease, we found positive relationships between obesity and heart failure, but not only for cardiovascular disease and stroke. Also, the findings of the researchers in the population of patients with COPD suggest that there is a significant positive relationship between obesity and obstructive sleep apnea. However, the results of cardiovascular disease are widely used for cardiovascular disorders, and most of the reported studies are based on information that can be generalized to cardiovascular disease patients with COPD. Additionally, patient information from electronic health records for all selected patients based on gender, age, smoking status, hospitalization period and general health status are extracted for predict Co-morbidities and can be related to the population of all respiratory patients. As a basis for future research on a variety of pulmonary diseases, such as asthma, COPD, emphysema and lung cancer, they are also useful.
\end{abstract}

Keywords: Body weight disorders; Co-morbidities; COPD patients; Obesity; Over weight

\section{Introduction}

\section{COPD and Mortality Risk Factors}

Chronic obstructive pulmonary disease (COPD) is an epidemic chronic pulmonary disease, which will be the third leading cause of death in the world by 2030. Although weight loss in patients with COPD is very common, previous studies have shown that about $65 \%$ of people with COPD have overweight or obesity, which can be due to physical inability and drug therapy. Obesity is one of the known risk factors for various diseases, such as diabetes and cardiovascular disease, as well as in patients with COPD. Additionally, obesity in COPD patients is associated with several other health risk factors, including signs of increased dyspnea, higher intake of inhaled drugs, and increased use of health care and decreased tolerance in excessive activity and fatigue. However, the Global Initiative for Chronic Obstructive Pulmonary Disease (GOLD), which provides evidence for the evaluation, diagnosis and treatment of COPD, focuses primarily on the prevention of weight loss, since weight loss in patients with COPD is at a higher risk than all of them mean increased mortality [1-3].

Chou chin Lan et al. [4] reported that in COPD patients with underweight had impairments and damages in exercise capacity, inspiratory muscle strength and tolerance exercise. Physical activity with supplemental 02 may be in case of overweight significantly but limited and improvement in exercise capacity and quality of life in COPD patients. We must be using of exercise program in clinic for keep-weight and decrease of that in COPD patients according to symptoms and signs that as an especially for them [4]. However, this mostly applies to patients with severe COPD where an increasing body mass index (BMI) is linearly associated with a better survival, while in patients with mild to severe COPD the lowest mortality risk occurs in normal to overweight situation of patients. Since both groups of COPD and obesity place a lot of healthcare in the health care system, it is important to get more information about the clinical features of overweight and obese patients with COPD, so that we can have a good strategy for them, with less economic costs draw less $[5,6]$. This knowledge can help in developing appropriate treatment strategies for patients with COPD in primary care and in addition reduce their health care costs.

\section{Co-morbidities with Overweight in COPD}

The results of recent studies in the world show that overweight and obesity are more epidemic in patients with COPD, with a higher incidence of disorders such as high blood 
pressure, osteoarthritis, diabetes, osteoporosis, anxiety disorder and a higher prevalence of heart failure in these patients than in patients with weight gain it is normal. Additionally, obesity was associated with an increase in the prescription drug for airway obstruction, which could be the cause of overweight in these patients [7]. Francesco Sava et al. [8] showed that in COPD patients with overweight are epidemic and often we can be seeing symptoms that frequency in clinical practice subjects. COPD patients are obesity, regard to having low airflow obstruction but they have less hyperinflation and had more improved peak VO2 than COPD patients with normal BMI. They have impairment in walking and other exercise tests despite of overweight (excess) but pulmonary rehabilitation will be best field and beneficial for improvement of symptoms and signs in clinic. In this research Francesco found that weight decrease strategies with exercise training both of home basic and clinical basic are great interesting between researchers and specialists and can be more beneficial aspects for decrease of Comorbidities in COPD patients [8]. Findings of the Co-morbidities disorder, along with the results of previous observations in the complete population of COPD patients, have been documented in complications such as diabetes, high blood pressure, osteoarthritis and osteoporosis. According to cardiovascular disease, we found positive relationships between obesity and heart failure, but not for cardiovascular disease and stroke. Also, the results of the researcher's findings in a population of COPD patients that there is a positive relationship between obesity and obstructive sleep apnea [9].

\section{Cardiovascular diseases and Obesity in COPD}

Findings of previous studies on the relationship between cardiovascular disease and COPD have not been more conclusive. Lambert et al. [10] in their studies consider obesity to be associated with an increased risk of cardiovascular disease and heart failure, while Cecere et al. [11] showed that there is a higher BMI in COPD patients than cardiovascular disease. However, cardiovascular disease outcomes are widely used for cardiovascular disorders, and most studies have been reported based on data that can be generalized for COPD patients with cardiovascular complications.

\section{Future Perspectives}

For further researches, it will be interesting to see whether weight loss in obese patients is associated with mild COPD progression to improve quality of life and reduce the number of pharmaceutical prescription [12]. In patients with asthma, weight loss is associated with positive outcomes in the symptoms of the patients, such as the improvement of breathlessness and endurance in exercise and daily activities. Since asthma symptoms are very similar to COPD, the promising results of weight loss in asthmatic patients support the need for research into the effect of weight loss in patients with COPD, and these results can be generalized for asthma patients $[13,14]$. Additionally, this information has been extracted from the electronic health records for all selected patients according to gender, age, smoking status, and can be related to the community of pulmonary patients and as a basis for future research, on types of pulmonary diseases, such as asthma, COPD, emphysema and lung cancer, is also useful.

\section{References}

1. Alibakhshi E, Lores L, Fiorillo R (2015) Physiological Factors Relevant to Exercise Tests in Pulmonary Rehabilitation of COPD Patients. J Sports Med Doping Stud 6: 167.

2. Garcia Rio F, Joan B Soriano, Marc Miravitlles, Luis Muñoz, Enric Duran Tauleria, et al. (2014) Impact of obesity on the clinical profile of a population based sample with chronic obstructive pulmonary disease. PLoS One 9: e105220.

3. Koniski ML, Salhi H, LahlouA, Rashid N, El Hasnaoui A (2015) Distribution of bodymass index among subjects with COPD in the Middle East and North Africa region: data from the Breath study. Int J Chron Obstruct Pulmon Dis 10: 1685-1694.

4. Lan CC, Huang HC, Yang MC, Lee CH, Huang CY, et al. (2014) Pulmonary Rehabilitation Improves Subjective Sleep Quality in COPD. Respir Care 59(10): 1569-1576.

5. Montes de Oca M, Tálamo C, Perez Padilla R, Jardim JR, Muiño A, et al. (2008) Chronic obstructive pulmonary disease and body mass index in five Latin America cities: the PLATINO study. Respir Med 102: 642-650.

6. Lisa DM Verberne, Chantal J Leemrijse, Ilse CS Swinkels, Christel E van Dijk, Dinny H de Bakker, et al. (2017) Overweight in patients with chronic obstructive pulmonary disease needs more attention: a cross-sectional study in general practice. npj Primary Care Respiratory Medicine 27: 63.

7. Vozoris NT, O Donnell DE (2012) Prevalence, risk factors, activity limitation andhealth care utilization of an obese, population-based sample with chronic obstructive pulmonary disease. Can Respir J 19(3): e18-e24.

8. Sava F, Perrault H, Brouillard C, Darauay C, Hamilton A, et al. (2012) Detecting improvements in dyspnea in COPD using a three-minute constant rate shuttle walking protocol COPD 9(4): 395-400.

9. Mannino DM, Thorn D, Swensen A, Holguin F (2008) Prevalence and outcomes of diabetes, hypertension and cardiovascular disease in COPD. Eur Respir J 32: 962-969.

10. Cecere LM, Littman AJ, Slatore CG, Udris EM, Bryson CL, et al. (2011) Obesity and COPD: associated symptoms, health-relatedquality of life, and medication use. COPD 8(4): 275-284.

11. Lambert AA, Putcha N, Drummond MB, Boriek AM, Hanania NA, et al. (2017) Obesity is associated with increased morbidity in moderate to severe COPD. Chest 151: 68-77.

12. (2017) Global Initiative for Chronic Obstructive Lung Disease. Global strategy for the diagnosis, management, and prevention of chronic obstructive pulmonary disease.

13. Guo Y, Zhang T, Wang Z, Yu F, Xu Q et al. (2016) Body mass index and mortality in chronic obstructive pulmonary disease: a dose-response meta-analysis. Medicine (Baltimore) 95(28): e4225.

14. Luppino FS, De Wit LM, Bouvy PF, Stijnen T, Cuijpers P, et al. (2010) Overweight, obesity, and depression: a systematic review and metaanalysis of longitudinal studies. Arch Gen Psychiatry 67(3): 220-229. 
Your next submission with Juniper Publishers will reach you the below assets

- Quality Editorial service

- Swift Peer Review

- Reprints availability

- E-prints Service

- Manuscript Podcast for convenient understanding

- Global attainment for your research

- Manuscript accessibility in different formats

( Pdf, E-pub, Full Text, Audio)

- Unceasing customer service

Track the below URL for one-step submission https://juniperpublishers.com/online-submission.php 